University of Wollongong

Research Online

Faculty of Social Sciences - Papers (Archive) Faculty of Arts, Social Sciences \& Humanities

$1-1-2017$

Canadian university students' gendered attitudes toward plagiarism

Sahar Bokosmaty

University of Wollongong, saharb@uow.edu.au

John F. Ehrich

Monash University, jehrich@uow.edu.au

Michelle J. Eady

University of Wollongong, meady@uow.edu.au

Kenton Bell

University of Wollongong, kb759@uowmail.edu.au

Follow this and additional works at: https://ro.uow.edu.au/sspapers

Part of the Education Commons, and the Social and Behavioral Sciences Commons

Research Online is the open access institutional repository for the University of Wollongong. For further information contact the UOW Library: research-pubs@uow.edu.au 


\title{
Canadian university students' gendered attitudes toward plagiarism
}

\begin{abstract}
Prior research on plagiarism has indicated that men may have a greater predisposition toward academic dishonesty than women. However, little research has been conducted using psychometrically tested instruments to validate such claims. To address this gap, a survey was conducted with 377 undergraduate students at a Canadian university on their attitudes toward plagiarism using a psychometrically validated instrument (the Attitudes Toward Plagiarism Questionnaire - Revised). Using differential item functioning/Rasch analysis, no overall differences in attitudes toward plagiarism based on gender were found. A descriptive analysis of both men and women revealed that while only a concerning minority of students reported engaging in plagiarist behaviours; there was a tendency for students to take a permissive stance on plagiarism. These results are discussed within the wider context of plagiarism research in higher education.
\end{abstract}

\section{Keywords}

students', plagiarism, university, toward, canadian, attitudes, gendered

Disciplines

Education | Social and Behavioral Sciences

Publication Details

Bokosmaty, S., Ehrich, J., Eady, M. J. \& Bell, K. (2019). Canadian university students' gendered attitudes toward plagiarism. Journal of Further and Higher Education, 43 (2), 276-290. 


\title{
Canadian university students' gendered attitudes toward plagiarism
}

\author{
Bokosmaty, S., ${ }^{1}$ Ehrich, J., ${ }^{2}$ Eady, M. ${ }^{1} \&$ Bell K. ${ }^{1}$ \\ ${ }^{1}$ School of Education, University of Wollongong, New South Wales, 2522, Australia \\ ${ }^{2}$ Faculty Education, Monash University, Victoria, 3800, Australia
}

Sahar Bokosmaty: saharb@uow.edu.au

$+61242215989$

John Ehrich: john.ehrich@monash.edu

$\underline{+60399052809}$

Michelle Eady: meady@uow.edu.au

$\underline{+61242213892}$

Kenton Bell: kenton@kentonville.com

$\underline{+17047246523}$

Word count 7147

Corresponding author: Sahar Bokosmaty, Faculty of Social Sciences, School of Education, University of Wollongong, NSW 2522, Australia; email saharb@uow.edu.au 


\begin{abstract}
Prior research on plagiarism has indicated that men may have a greater predisposition toward academic dishonesty than women. However, little research has been conducted using psychometrically tested instruments to validate such claims. To address this gap, a survey was conducted with 377 undergraduate students at a Canadian university on their attitudes toward plagiarism using a psychometrically validated instrument (the Attitudes Toward Plagiarism Questionnaire - Revised; Howard, Ehrich, \& Walton, 2014). Using Differential Item Functioning/Rasch analysis, no overall differences in attitudes toward plagiarism based on gender were found. A descriptive analysis on both men and women revealed that while only a concerning minority of students reported engaging in plagiarist behaviours; there was a tendency for students to take a permissive stance on plagiarism. These results are discussed within the wider context of plagiarism research in higher education.
\end{abstract}

Keywords: Canada; plagiarism; academic dishonesty; attitudes; university; education 


\section{Introduction}

Plagiarism, whether intentional or unintentional, is the act of using the works or words of others without crediting the source (therefore implicitly or explicitly claiming it as one's own). Plagiarism is a serious form of academic misconduct that undermines the validity of academic degrees, students' achievements, and the integrity of the academic institutions awarding the degrees. There is a recent increase in plagiarism research, particularly identifying the methods used to commit plagiarism, accurate measurement of plagiarism prevalence, and new methods of detection (Jiang, Emmerton, \& McKauge 2013).

The serious problem of plagiarism has occured in universities worldwide at least since the mid-eighteenth century (Quah, Stewart, \& Lee 2012), with high rates of plagiarism being reported in Australia, China, North America, and the United Kingdom (Ehrich, Howard, Mu, \& Bokosmaty, 2016).

The extent of this problem is illustrated by research in which more than one-third of university students admit to plagiarist behaviours (Christensen-Hughes, \& McCabe, 2006; McCabe, 2005). Additionally, it is suggested that these rates of plagiarism are likely even higher than reported and that incidences of plagiarism are on the rise (Selwyn, 2008; Walker, 2010). Furthermore, there is a growing amount of research focused on the ubiquitous plagiarism-detection platform Turnitin (GrahamMatheson \& Starr 2013, Heckler, Rice, \& Hobson Bryan 2013, Thompsett \& Ahluwalia 2010, Heather 2010, Bruton and Childers 2016, Penketh \& Beaumont 2014). However, Turnitin is far from the only plagiarism detection software in use, others include PlagScan, URKUND, and VeriCite; each with varying limitations on detection such as ghost writing (Lines, 2016). 
Plagiarism is a highly complex issue, and as such, there is no simple explanation for why students engage in such behaviour. In fact, a multitude of interrelated factors likely contributes to university students' decisions on whether to engage in plagiarist behaviours (Park, 2003). These include poor language skills (Devlin \& Gray, 2007; $\mathrm{Mu}, 2010$ ), misapprehensions about what constitutes plagiarist behaviours (Jurdi, Hage, \& Chow, 2011; Marshall \& Garry, 2006; Ryan et al., 2009; Gullifer \& Tyson 2014), academic, extra-curricular and employment pressures on students (Curtis \& Popal, 2011; Ehrich, Howard, Mu, \& Bokosmaty, 2016; Koh, Scully, \& Woodliff, 2011), differing cultural perspectives and understandings (Ehrich et al., 2016; Marshall \& Garry 2006; Pickering \& Hornby 2005; Sowden, 2005) and other factors such as age, gender, and personality (Caruana, Ramaseshan, \& Ewing, 2000; Jurdi et al., 2011; Park, 2003; Hensley, Kirkpatrick, \& Burgoon, 2013). Other reasons that have been suggested to exacerbate plagiarism include the growing availability of electronic resources (Jiang et al., 2013; Gullifer \& Tyson 2010; Postle 2009) and students' permissive attitudes toward plagiarism (Baruchson-Arbib \& Yaari, 2004). Additionally, others suggest educators choose not to take appropriate action when students plagiarize (McCabe, Trevino, \& Butterfield, 2001), educators and students disagreeing on what constitutes plagiarism (Chen \& Chou, 2017), educators themselves not understanding what constitutes plagiarism (Gullifer \& Tyson, 2014) and universities failing at sustainable forms of anti-plagiarism management (Sutherland-Smith, 2010). 


\section{Gender and plagiarism}

The primary interest of the study is the effect of gender ${ }^{1}$ on attitudes toward plagiarism and academic dishonesty. Gender is considered to be an important factor in the prediction of plagiarist behaviour (Honig \& Bedi, 2012) with many studies building on the seminal work Student Dishonesty and Its Control in College by Bowers (1964) and replicated by others (e.g., Newstead, Franklyn-Stokes, \& Armstead 1996; Jensen, Arnett, Feldman \& Cauffman, 2002). The rationale behind this is that men, due to their differing gendered expectations and socialisation, tend to indulge in riskier behaviours than women do (cf., Brynes, Miller, \& Schafer, 1999; Charness \& Gneezy, 2012) and specific types of academic dishonesty (Yardley, Rodriguez, Bates, \& Nelson, 2009). Furthermore, Honig and Bedi (2012) argue that the stereotypical attributes associated with men's behaviour, such as independence, self-assertiveness, and competitiveness juxtapose with feminine traits such as compassion, sympathy, and higher moral standards which pre-dispose them more towards academic dishonesty than women. Honig and Bedi's contention is in alignment with the foundational work on hegemonic masculinity and emphasised femininity by Connell (1987). These traits shape behaviours to a certain extent, and hence, would indicate men are more likely to engage in plagiarism resulting from their greater risk-taking and competitive natures (Honig \& Bedi, 2012).

There is substantial evidence suggesting men are more predisposed toward academically dishonest behaviour, such as cheating, than women (cf., Davis et al., 1992; Finn \& Frone, 2004; Franklyn-Stokes \& Newstead, 1995; McCabe \& Trevino,

\footnotetext{
${ }^{1}$ For the purposes of this paper, men/male and women/female are considered correlated. Because gender roles are social constructed and continually influx (West \& Zimmerman, 1987, 2009), the use of the gendered dichotomy of men/male and women/female is limiting, reductive, and reifying but is a limitation inherent in the data. While this paper's approach does not fully acknowledge the scope of sexual and gendered differences, the goal is not to further reify a false dichotomy or essentialist thinking.
} 
1997; Newstead et al. 1996). Reviews of the literature by Crown and Spiller (1988) and Whitley (1998) also suggest that men are more predisposed toward academic cheating behaviour than women. Similarly, Coleman and Mahaffey (2000) found that women are more intolerant of cheating behaviour in universities than men. More recently, Roig and Caso (2005) investigated 565 undergraduate psychology students and found that while there are no significant gender differences in plagiarist behaviour, significantly more men than women used fraudulent excuses when submitting late academic work.

However, later studies investigating gender effects on plagiarist behaviour tell a different story. For example, Martin, Rao, and Sloan (2009) found that women commit more acts of plagiarism than men do. Martin et al. investigated the Turnitin results (plagiarism detection software) of 158 participants (business graduates \& undergraduates) in business administration courses and found that women plagiarised significantly more than men did. By contrast, other higher education studies investigating rates of plagiarism have not verified any significant gender effects (e.g., Biliæ-Zulle, Frkoviæ, Turk, Azman, \& Mladen, 2005; Ellery, 2008; Walker, 2010).

Clearly, the impact of gender on plagiarist behaviour has not been determined, though current trends in research would suggest that gender might not be a significant factor in plagiarist behaviour by university students. Of particular interest is the investigation of attitudes toward plagiarism, not necessarily acts. If one gender were more predisposed toward plagiarism than the other was, then this would manifest as a softer (or more trivial) attitude toward plagiarism in general. Based on the review of studies, the hypothesis is that men would exhibit softer or more trivial attitudes toward plagiarism than women. 


\section{Research methods}

While there has been a recent trend in plagiarism research to incorporate online plagiarism detecting software such as Turnitin to facilitate research into plagiarism behaviour (Martin et al., 2009; Walker, 2010), the majority of research into plagiarism in higher education relies on self-report questionnaires as the main instruments of data collection (Ehrich, Howard, Tognolini, \& Bokosmaty, 2015; Gururajan \& Roberts, 2005; Walker, 2010). A potential problem in survey research is that some respondents can under report undesirable behaviour and over report desirable behaviour (Krumpal, 2011; Tourangeau \& Yan, 2007). However, to address this issue, we ran a rigorous and comprehensive psychometric analysis using a modern measurement approach (i.e., Rasch analysis). Rasch analysis is sensitive to detecting inconsistent response patterns in that if a respondent gives erratic and inconsistent answers, then this would appear in the analysis (Tennant \& Conaghan, 2007).

While these questionnaire-based studies have begun to establish the prevalence of plagiarism and some of the potential precursors to students' engagement in plagiarist behaviours, the frequent lack of psychometric analyses of the survey instruments adopted remains a common oversight (Ehrich et al., 2015; Gururajan \& Roberts, 2005). That is, while there is some preliminary research on university students' plagiarism attitudes, beliefs and practices, these findings are based on data generated from survey instruments for which validity and reliability data does not yet exist (Austin, Simpson, \& Reynen, 2007; Christensen-Hughes \& McCabe, 2006; Kloda \& Nicholson, 2005; Montuno, Davidson, Iwasaki, \& Mori, 2012). Without psychometric evaluation, it remains unclear whether these scales measure the intended construct (in this case, plagiarism attitudes) in a valid and reliable manner. Consequently, educator or institutional policies, practices, and interventions enacted based on data from tools 
that have not been psychometrically evaluated is problematic (Ehrich et al., 2016; Gururajan \& Roberts, 2005).

To address this issue of measurement, the current study sought to administer a psychometrically evaluated instrument (the Plagiarism Attitudes Questionnaire Revised; Howard et al., 2014) to investigate students' attitudes toward plagiarism. This scale has the benefit of rigorous psychometric evaluation (e.g., factor analysis, reliability analysis, and Rasch analysis; Howard et al., 2014) in the Australian context. The current study represents the first administration of this scale in the Canadian context. Specifically, an investigation into the effect of gender on Canadian university students' attitudes regarding the factors that exacerbate plagiarism; the justification for plagiarism; the severity of plagiarism; and the penalty for plagiarism. This investigation was undertaken to not only supplement current research on gender effects on students' attitudes toward plagiarism, but also to provide data from a psychometrically established scale against which to compare current policies, practices, and findings. In addition, because prior research has found that pressure is significantly related to students' attitudes toward plagiarism (Bannister \& Ashworth, 1998; Curtis \& Popal, 2011; Ehrich et al., 2016), the study investigated the relationships between students' self-reported levels of pressure and their degree of severity of attitude toward plagiarism. Finally, a basic descriptive analysis on undergraduate university students' attitudes toward plagiarism was conducted to compare findings with other domestic and international higher education research.

\section{Method}

\section{Participants}

Participants were domestic undergraduate students $(n=377)$ enrolled in a first-year introductory psychology course at a Canadian university. They were 
recruited through a university undergraduate research participant pool, which provided partial credit toward their psychology course for participation in research. In all cases, participants anonymously completed the online questionnaire. Students who volunteered to participate in the study were made aware that their lecturers would not have access to their data to promote the veracity of responses. The resultant sample consisted of more women $(n=254)$ than men $(n=123)$, which is largely consistent with the demographic makeup of the students in this program. All students were young adults of around the same age $\left(M_{\text {men }}=20.15, S D=3.19 ; M_{\text {women }}=20.04, S D=\right.$ 3.35). A majority of the participants were first-year $(n=233)$ and second-year students $(n=81)$, with a smaller number of third-year $(n=39)$ and fourth-year students $(n=24)$. All first-year students participate in an induction, which describes in detail what plagiarism is, and the policies of the university.

\section{Instrument}

Following the protocols of Howard et al.'s (2014) initial psychometric evaluation of the Attitudes Toward Plagiarism Scale - Revised, an online version of the 36-item questionnaire was used to measure students' plagiarism attitudes and beliefs. Using exploratory factor analysis (EFA), Cronbach's Alpha, and Rasch analyses, this scale was found to have three functional and reliable subscales at the scale and item level in a sample of Australian tertiary students (Howard et al., 2014). In the present study participants indicated their level of agreement with each statement using an 11-point Likert scale ranging from 'strongly disagree' (1) to 'strongly agree' (11). For comparability with the results of Howard et al.'s (2014) study, the response categories were re-categorized into five response categories, corresponding to a 5-point Likert scale (i.e., $1=$ strongly disagree, $2-5=$ disagree, $6=$ neutral, $7-10=$ agree, $11=$ strongly agree). 


\section{Results}

\section{Rasch Analysis}

Given the differences in the sample (Australian vs. Canadian), administration method (face to face vs. online), and response categories (5-point vs. 11-point) psychometric and Rasch analyses were again conducted on the current data to evaluate the validity and reliability of this scale. Whereas traditional psychometric analyses describe the data collected at the subscale level, Rasch analyses (a form of item response theory) provides analytical data at the item level to inform the construction of measurement instruments (for a detailed description of these analyses, see Appendix A).

Rasch analyses were run using the Polytomous Rasch Model (PRM) with partial credit parameterization. Analyses were run using Rasch Unidimensional Measurement Modeling (RUMM) 2020 software (Andrich, Sheridan, \& Luo, 2010). For a detailed description of Rasch analysis, its applications and interpretation of statistics see Tennant and Conaghan (2007).

The analyses paralleled previous findings (Howard et al., 2014) by indicating the presence of three functional subscales with (largely) reliable psychometric properties. These were: (1) factors that exacerbate plagiarism, consisting of 10 items (Items 9, $12,18,22,23,26,29,30,34, \& 36$ ); (2) justification for plagiarism, consisting of 6 items (Items 1, 2, 3, 6, 11, \& 27); and (3) severity and penalty, consisting of 7 items (Items $4,7,15,16,17,19, \& 25)$. These results are consistent with the findings of Howard et al. (2014), with three main exceptions. First, in the current study, the first subscale (Factors that Exacerbate Plagiarism) functioned best as a 10-item scale, compared to Howard et al.'s findings of an 8- item subscale. Additionally, three items were found to misfit in the current study (Items 21, 28, \& 33), which functioned well 
in Howard et al.'s (2014) analyses. Lastly, in the present study, subscale 3 (Severity and Penalty) functioned best as a 7-item scale, contrasting the 8-item subscale suggested by Howard et al. (2014). Question 5 was also found to misfit in these analyses and was removed. Nevertheless, Rasch analysis confirmed these three subscales as measuring unidimensional constructs, all with at least reasonable psychometric properties. Mean scores of each subscale can consequently be assumed to provide an accurate index of the latent construct of interest (factors that exacerbate plagiarism; the justification for plagiarism; the severity of plagiarism; and the penalty for plagiarism). The analyses that follow report only the data for items with a good fit to the Rasch model.

\section{Gender analysis}

To determine the effect of gender on respondent's attitudes toward plagiarism analyses were run on each subscale. Within the RUMM 2020 program, an Analysis of Variance (ANOVA) was run on the mean locations of all items and persons within the subscale. The spread of mean locations for persons per subscale are depicted graphically as a Person Frequency Distribution map (see Figure 1). Next, Differential Item Functioning (DIF) was run on each item in the subscale to investigate gender bias per item. DIF is achieved by conducting ANOVAs on the standardized residuals for persons and items. Specifically, a two-way ANOVA is run on the class intervals of the comparison group, yielding a main effect of class interval, a main effect of the comparison group, as well as any interaction between these effects. Significant results (after Bonferroni adjustment) indicate the presence of DIF. DIF can also be detected by each item's Item Characteristic Curves (ICCs) which plot the observed values (i.e., person estimates) against the expected values as represented by a theoretical S-shaped 
curve. Incongruent group curves can indicate the presence of group bias. This and all subsequent DIF analyses followed this approach.

Subscale 1: Factors that Exacerbate Plagiarism. Overall, men (mean location $=-2.254, S D=1.50$ ) had slightly more permissive attitudes toward plagiarism than women (mean location $=-2.151, S D=1.65$ ) but this was not significant, $F<1$ (see Figure 1).

[Figure 1 near here]

DIF analysis with Boferroni adjusted alpha $=.005(.05 / 10)$ revealed a significant gender effect $F=15.14, p<.0002$ (see Figure 2) on item 26 - Sometimes I copy a sentence or two just to become inspired for further writing. From Figure 2, uniform DIF can be seen from the incongruent group graphs. Women, who are represented by the red line, are more likely to copy sentences for inspiration than men (depicted by the blue line).

\section{[Figure 2 near here]}

Subscale 2: Justification for Plagiarism. An ANOVA revealed that there were no significant differences between men (mean location $=-0.236, S D=.97$ ) and women $($ mean location $=-0.235, S D=1.00), F<1$ (see Figure 3$)$. DIF analyses per item also revealed no significant differences on any items at Bonferroni adjusted alpha $=.008(.05 / 6)$

[Figure 3 near here]

Subscale 3: Severity and Penalty. An ANOVA revealed that while men (mean location $=-1.417, S D=1.13$ ) had slightly more permissive attitudes toward plagiarism than women (mean location $=-1.639, S D=1.26$ ), in this subscale, this was 
not significant, $F(1,376)=2.75, p=.09$ (see Figure 4$)$. No DIF was detected for any item at Bonferroni adjusted alpha $=.007(.05 / 7)$.

\section{[Figure 4 near here]}

\section{Pressure analysis}

Spearman rank correlations were run for each subscale with: (1) students' perceptions of the pressure they place on themselves to achieve academically; and (2) students' perceptions of the pressure placed on them by others to achieve academically. A weak but significant negative correlation was found between all subscales and the pressure students' placed on themselves to achieve academically (Subscale 1: $r=-0.14, p<.01$; Subscale 2: $r=-0.12, p<.02$; Subscale 3: $r=-0.18$, $p<.001)$. Interestingly, this suggests that the more pressure students placed on themselves, the less permissive their attitudes were towards plagiarism (and vice versa). No significant correlations were found between the subscales and students' ratings of the pressure placed on them to achieve academically by others (all ps > .05).

\section{Descriptive Analysis}

Subscale 1: Factors that Exacerbate Plagiarism. Descriptive statistics for this subscale are provided in Table 1. Attitudes toward plagiarism in this scale revealed that more than one-quarter of all students $(25.7 \%)$ reported copying sentences from source materials to facilitate writing (Q26) and that more than one-fifth of student respondents (23.9\%) believed that plagiarism was only a 'big deal' if it comprised a substantial portion of the academic work (Q34). These results highlight a concerning minority of students with relatively permissive attitudes toward plagiarism. While only a small percentage of students (3.4\%), admitted to repeated plagiarism offences 
(because they have not been caught), this figure becomes increasingly concerning if true of all Canadian university students.

In identifying potential precursors of plagiarist behaviours, nearly one-fifth (19.9\%) of respondents were aware of others' plagiarist behaviours and, therefore felt tempted to engage in such behaviour themselves (Q22). Another concerning issue was that more than $13 \%$ of respondents would feel the temptation to plagiarise if given permission to copy others' work (Q30) and that more than 7\% of students felt that this practice was neither harmful nor wrong. Perhaps most strikingly, nearly $10 \%$ of respondents felt that plagiarism was necessary $(\mathrm{Q} 29)$ and does no harm to a university degree (Q18). Although on average students' attitudes toward these issues demonstrated their opposition to plagiarism, a worryingly high percentage of students held permissive attitudes toward these statements.

\section{[Table 1 near here]}

Subscale 2: Justification for Plagiarism. Mean responses and the overall percentage of response per item are provided in Table 2. This subscale mostly concerned the issue of self-plagiarism. A majority of students (> 54\%) indicated a lack of awareness that self-plagiarism is a serious form of academic dishonesty. This finding might explain the relatively permissive attitudes regarding feeling no guilt when copying sentences from prior work (43\%) and the belief that self-citation of previous work is not required when completing current work (24.9\%). While these questions can be interpreted as a lack of awareness of what constitutes plagiarism per se, the responses to other items have more severe implications. That is, some respondents reported feeling that plagiarism was inevitable because of language limitations or because of repeated descriptions of concepts ( $>38 \%)$. Furthermore, more than a third of students felt that there should be light penalties for plagiarism 
because they are undergraduates and are new to the academic community. Overall, these findings indicate a pervasive lack of understanding of plagiarism and a perception that plagiarism is inevitable (and should be treated as such) due to students' novice status.

\section{[Table 2 near here]}

Subscale 3: Severity and Penalty. Mean responses and the percentage agreement with item statements are provided in Table 3. Regarding the severity of plagiarism, $34 \%$ of students believed that plagiarism was not as bad as stealing an exam, suggesting students' conceptual divide between 'stealing' and 'plagiarism'. However, this permissive attitude toward plagiarism is qualified to an extent by the lesser belief $(>14 \%)$ that the theft of words is not as serious as the theft of material assets (Q19). Consistent with this finding is that nearly $10 \%$ of students believed that plagiarism did not undermine independent thought and should therefore be considered acceptable if the submitted work is otherwise of high quality. Moreover, approximately $7 \%$ of students believed that plagiarism was a trivial issue (Q25). A minority of students $(5.8 \%)$ believed that poor writing skills excused plagiarist behaviour. The findings of this subscale indicated an overall stance against plagiarism, yet a concerning proportion of students who did not view plagiarism as a lesser form of academic dishonesty.

\section{[Table 3 near here]}

\section{Discussion}

The current study aimed to investigate students' self-reported attitudes toward plagiarism using a psychometrically validated scale. The principal goals were to 1) determine the effect of gender on the latent construct of attitudes toward plagiarism; 2) investigate the relationship between pressure and severity of attitude toward 
plagiarism; and 3) conduct a descriptive analysis to attain further perspectives on undergraduate Canadian psychology students' attitudes toward plagiarism.

Prior research investigating the effect of gender on plagiarism has revealed mixed findings. Furthermore, in many cases, the instruments/scales used in such comparison studies have not been psychometrically validated, casting doubt on the accuracy of the findings. Hence, the degree to which gender affects attitudes toward plagiarism has not been tested using a rigorous measurement model (i.e., Rasch analysis).

The Rasch analysis revealed no significant effects of gender when analysing by subscale. The overall findings indicate that men are not predisposed toward having more permissive attitudes toward plagiarism than women. It should be noted that the present findings are important in that this is the first study of its kind to compare gender effects on undergraduate students' using a psychometrically validated instrument that has been tested rigorously using a modern measurement approach (Howard et al., 2014).

The findings are in line with prior studies that found no significant gender effects on plagiarism (Biliæ-Zulle et al., 2005; Ellery, 2008; Walker, 2010). Arguably, it may be that those previous findings indicating high levels of academic dishonesty from men are artefacts of their times. That is, earlier studies that indicated strong gender effects of academic dishonesty in men might be less relevant today as the gender roles of men and women become less distinct and converge (Goldin, 2014). Of course, this is highly speculative, and the investigation lacks the capacity to support such assertions. However, this would be an interesting avenue to explore in future research.

While no significant differences were found at the subscale level, there was some evidence of a minor gender effect at the individual item level. A key finding was that women were significantly more likely than men to copy a few sentences to inspire 
their writing. While this practice in itself is not necessarily an undesirable behaviour rote learning when acquiring language is a common practice (Harmer, 2015) - such practices may become habit forming and may facilitate the copying of work (Sowden, 2005). If such practices do in fact lead to plagiarist behaviour, then the current finding may help explain Martin et al.'s (2009) finding which indicated that women were committing more acts of plagiarism than men (based on Turnitin results).

The descriptive analysis on the whole sample indicated that the severity of students' attitudes toward plagiarism was inconsistent, demonstrated a hierarchy of values in some cases, and was largely contingent on specific aspects and factors related to plagiarism. For example, students' attitudes were most permissive when asked questions about justifications for plagiarism (subscale 2) and, by contrast, were most severe toward plagiarism when asked about factors that exacerbate plagiarism (subscale 1). Specifically, subscale 2 contained questions pertaining to students' attitudes toward self-plagiarism, with the majority of students feeling that selfplagiarism does not constitute serious academic misconduct. This finding is consistent with Canadian (Christensen-Hughes \& McCabe, 2006; Jurdi et al., 2012) and international research indicating undergraduate students' lack of clarity regarding what constitutes a plagiarist behaviour (Crisp, 2007; Devlin \& Gray, 2007; Ehrich et al., 2016; Ehrich et al., 2015; Hu \& Lei, 2012; Marshall \& Garry 2006; Mu, 2010; Park, 2003; Song-Turner, 2008). It also highlights the potential influence of institutional factors in the development of students' beliefs and attitudes. Specifically, this finding may be a result of the students' institution not having a clause about selfplagiarism in their academic misconduct policy. Regardless of the specific source(s) of these attitudes, the permissiveness of students' attitudes on self-plagiarism raises questions about their understanding of the proper protocols in academic writing. 
Students' more permissive attitudes were also evident in the context of their more novice status when it comes to academic writing. For example, over one-third of students felt that penalties for plagiarist behaviours should be minor for academic newcomers, a finding that is largely consistent with previous findings (ChristensenHughes, \& McCabe, 2006; Ehrich et al., 2015). Such permissive attitudes are also consistent with a common notion among students that plagiarism is trivial or "no big deal" (Park, 2003, p. 476). Interestingly, nearly half of the sample considered there to be a finite number of ways to combine words, which rendered it acceptable to plagiarize because there are limited ways a description can be written. By logical extension, this suggests that if a large number of people write on the same concept, topic, or idea there is bound to be overlap in the text of this writing. While there is some truth to this, it also suggests a convenient pretext for avoiding the often-arduous task of paraphrasing in one's own words. This finding is also congruent with studies that have associated plagiarist behaviour with poor second language (L2) writing and academic skills (Devlin \& Gray, 2007; Sowden, 2005). However, it is difficult to determine the extent to which this permissive attitude to plagiarism in the current study is a result of undeveloped writing skills or a language-related difficulty in paraphrasing and summarising (Roig, 2001).

Even though the attitudes toward plagiarism in Subscale 3 (Severity and Penalty) were significantly less permissive than Subscale 2 (Justification for Plagiarism), they still reflected highly permissive attitudes in some regards. For example, more than two-thirds of the sample believed that plagiarism is not as bad as stealing an exam. This suggests that students ascribe to a 'hierarchy of values' in that certain forms of academic misbehaviour are rated less serious than others (Aggarwal, Bates, Davies, \& Khan, 2002). Clearly, in this case, plagiarism is marginalized compared to the 
seriousness of stealing an exam paper. Such permissive attitudes toward plagiarism again highlight a lack of awareness that plagiarism is a form of academic dishonesty, a finding that is consistent with previous studies (Austin et al., 2007; ChristensenHughes \& McCabe, 2006).

In contrast to these more permissive attitudes toward plagiarism, responses to Subscale 1 (Factors that Exacerbate Plagiarism) demonstrated a more severe stance against plagiarism. A concerning minority continued to indicate their temptation and engagement in plagiarist behaviours. For example, one-fifth were tempted to plagiarize because of a perception that plagiarism is a commonplace practice. This finding is consistent with other studies that highlight the predictive strength of perceptions of peer misconduct (Jurdi et al., 2011; Montuno et al., 2012). This finding suggests that plagiarism may be more prevalent among students than the $3.4 \%$ who admitted to engaging in repeated plagiarist behaviour in the survey (for higher prevalence estimates see Christensen-Hughes \& McCabe, 2006; McCabe, 2005).

Another concerning result is that nearly a quarter of respondents regarded limited amounts of plagiarism as trivial. This finding is similar to earlier research by Christensen-Hughes and McCabe (2006), which indicated that $37 \%$ of undergraduates copy sentences from written sources without adequate citation. Engaging in limited plagiarist behaviour is therefore viewed by many students as tolerable, because they view this type of plagiarism as not too excessive. Further, more than a quarter of students reported copying sentences for inspiration to facilitate writing (which may also highlight their lack of understanding of plagiarism, since less than $5 \%$ of students reported engaging in plagiarist behaviours). The analysis revealed that this behaviour was significantly more prevalent in women than in men. 
Extending previous findings, the current study found that as students placed more pressure on themselves to succeed academically, this tended to coincide with stronger views against plagiarism. This finding supports the studies of de Bruin and Rudnic (2007) and Haines, Diekhoff, LaBeff and Clark (1986), both of which indicated that plagiarism attitudes were associated with students' levels of performance and conscientiousness. That is, better performing students with strong academic goals tended to have more severe attitudes toward plagiarism than poorer performers and less conscientious ones. The current data extends previous findings to suggest that plagiarist attitudes were most severe from students who placed the highest level of pressure on themselves.

While it is arguable whether permissive plagiarist attitudes are synonymous with plagiarist behaviours, research suggests that the two are in fact related. For instance, Jurdi et al. (2011) found perceptions of academic dishonesty significantly predict selfreported academically dishonest practices. In fact, these perceptions and beliefs were also positively correlated with the frequency of these academically dishonest behaviours. This finding, which receives further research support (Bolin, 2004; Jensen et al., 2002; Murdock \& Anderman, 2006), suggests that plagiarist attitudes provide, at the very least, an understanding about students' propensities for plagiarist acts and the situations in which these are most prevalent. As such, data on students' plagiarism attitudes using valid and reliable data collection tools is paramount to inclusive action (i.e., initiatives that consider not only the institutional perspective but also realities of students and staff) to prevent plagiarism before it occurs. The finding that a large proportion of students trivialise plagiarism does not indicate that students are inherently dishonest or unethical. Rather, such findings indicate that students are often uneducated, unpractised, and confused when it comes to proper citation. 


\section{Conclusion}

The current study provides initial data using a psychometrically evaluated data collection instrument, from which to: (1) understand the effect (or lack thereof) of gender on attitudes toward plagiarism; (2) understand students' attitudes toward plagiarism; (3) compare previous survey-based research findings; and (4) begin to generate proactive plagiarism initiatives that acknowledge students' perspectives. In the context of the current findings, this might include explicit instruction in the proper use of others' (and own) materials, why this is important and the consequences (both intellectual and academic) for circumventing these requirements. Further, the current results indicate that it is too simplistic to reduce such a complex phenomenon into a simple dichotomy. Student attitudes range from permissive to severe depending upon a range of factors related to plagiarism (e.g., whether it is using one's own work or the work of another, whether punishment is likely and severe, and whether others also engage in plagiarist practices). Utilising the Attitudes Toward Plagiarism

Questionnaire - Revised (Howard et al., 2014) can reveal for educators a valid and reliable description of students' perspectives on plagiarism using this psychometrically validated tool. 


\section{References}

Aggarwal, R., Bates, I., Davies, J. G., \& Khan, I. (2002). A study of academic dishonesty amongst students at two pharmacy schools. Pharmaceutical Journal, $269,529-533$.

Andrich, D., Sheridan, B., \& Luo, G. (2010). RUMM2030: A Windows program for the Rasch Unidimensional Measurement Model. Perth, WA: RUMM Laboratory. Austin, Z., Simpson, S., \& Reynen, E. (2007). 'The fault lies not in our students, but in ourselves': Academic honesty and moral development in health professions education - results of a pilot study in Canadian pharmacy. Teaching in Higher Education, 10(2), 143-156.

Bannister, P., \& Ashworth, P. (1998). Four good reasons for cheating and plagiarism. In C. Rust (Ed.), Improving student learning symposium (pp. 233-241). Oxford, UK: Oxford.

Baruchson-Arbib, S., \& Yaari, E. (2004). Printed versus Internet plagiarism: A study of students' perception. International Journal of Information Ethics, 1(6), 1-7.

Biliæ-Zulle,L., Frkoviæ,V., Turk, T., Azman, J., \& Mladen, P. (2005). Prevalence of plagiarism among medical students. Croatian Medical Journal, 46(1):126131.

Bolin, A. U. (2004). Self-control, perceived opportunity, and attitudes as predictors of academic dishonesty. Journal of Psychology, 138(2), 101-114.

Bowers, W. (1964). Student dishonesty and its control in college. New York: Bureau of Applied Social Research, Columbia University.

Bruton, S., \& Childers, D. (2016). The ethics and politics of policing plagiarism: A qualitative study of faculty views on student plagiarism and Turnitin®. Assessment \& Evaluation in Higher Education, 41(2), 316-330. 
Brynes, J. P., Miller, D. C., \& Schafer, W. D. (1999). Gender differences in risk taking: A meta-analysis. Psychological Bulletin, 125, 367-383.

Caruana, A., Ramaseshan, B., \& Ewing, M. T. (2000). The effect of anomie on academic dishonesty honesty among university students. The International Journal of Educational Management, 14(1), 23-37.

Charness, G., \& Gneezy,U.( 2012). Strong evidence for gender differences in risk taking. Journal of Economic Behavior \& Organization, 83, 50-58.

Chen, Y., \& Chou, C. (2017). Are we on the same page?: College students' and faculty's perception of student plagiarism in Taiwan. Ethics \& Behavior, 27(1), $53-73$.

Christensen-Hughes, J. M., \& McCabe, D. L. (2006). Academic misconduct within higher education in Canada. Canadian Journal of Higher Education, 36(2), 1-21.

Coleman, N., \& Mahaffey, T. (2000). Business student ethics: Selected predictors of attitudes toward cheating. Teaching Business Ethics, 4(2), 121-136.

Connell, R. W. (1987). Gender and power: Society, the person, and sexual politics. Cambridge: Polity.

Crisp, G. T. (2007). Staff attitudes to dealing with plagiarism issues: Perspectives from one Australian university. International Journal of Educational Integrity, 3(1), 3-15.

Crown, D. F., \& Spiller, M. S. (1998). Learning from the literature on collegiate cheating: A review of empirical research. Journal of Business Ethics, 17(6), $683-700$.

Curtis, G. J., \& Popal, R. (2011). An examination of factors related to plagiarism and a five-year follow-up of plagiarism at an Australian university. International Journal for Educational Integrity, 7(1), 30-42. 
Davis, S. F., Grover, C. A., Becker, A. H., \& McGregor, L. N. (1992). Academic dishonesty: Prevalence, determinants, techniques, and punishments. Teaching of Psychology, 19, 16-20.

de Bruin, G. P., \& Rudnick, H. (2007). Examining the cheats: The role of conscientiousness and excitement seeking in academic dishonesty. South African Journal of Psychology, 37, 153-164.

Devlin, M., \& Gray, K. (2007). In their own words: A qualitative study of the reasons Australian university student plagiarise. Higher Education Research and Development, 26(2), 181-198.

Ehrich, J., Howard, S., Mu, C., \& Bokosmaty, S. (2016). A comparison of Chinese and Australian university students' attitudes toward plagiarism. Studies in Higher Education. Online first doi: 10.1080/03075079.2014.927850

Ehrich, J., Howard, S., Tognolini, J., \& Bokosmaty, S. (2015). Measuring attitudes toward plagiarism: Issues and psychometric solutions. Journal of Applied Research in Higher Education. Advance online publication.

Ellery, K. (2008). Undergraduate plagiarism: A pedagogical perspective. Assessment \& Evaluation in Higher Education, 33(5), 507-516.

Finn, K. V., \& Frone, M. R. (2004). Academic performance and cheating: Moderating role of school identification and self-efficacy. Journal of Educational Research, 97, 115-122.

Franklyn-Stokes, A.,\& S.E. Newstead. 1995. Undergraduate cheating: who does what and why? Studies in Higher Education, 20(2), 159-72.

Goldin, C. (2014). A grand gender convergence: Its last chapter. American Economic Review, 104(4): 1-30. 
Graham-Matheson, L., \& Starr, S. (2013). Is it cheating or learning the craft of writing?: Using Turnitin to help students avoid plagiarism. Research in Learning Technology, 21(1), 17218.

Gullifer, J., \& Tyson, G. A. (2010). Exploring university students' perceptions of plagiarism: A focus group study. Studies in Higher Education, 35(4), 463-481.

Gullifer, J., \& Tyson, G. A. (2014). Who has read the policy on plagiarism?:

Unpacking students' understanding of plagiarism. Studies in Higher Education, $39(7), 1202-1218$.

Gururajan, R. \& Roberts, D. (2005). Attitude towards plagiarism in information systems in Australian universities. Paper presented at the Asia Pacific Conference on Information Systems. Bangkok, Thailand.

Haines, V. J., Diekhoff, G. M., LaBeff, E. E., \& Clark, R. E. (1986). College cheating: Immaturity, lack of commitment and the neutralising attitude. Research in Higher Education, 25, 342-354.

Harmer, J. (2015). The practice of English language teaching ( $5^{\text {th }}$ ed.). Harlow, England: Longman.

Heather, J. (2010). Turnitoff: Identifying and Fixing a Hole in Current Plagiarism Detection Software. Assessment \& Evaluation in Higher Education, 35(6), $647-660$.

Heckler, N. C., Rice, M., \& Hobson Bryan, C. (2013). Turnitin Systems. Journal of Research on Technology in Education, 45(3), 229-248.

Hensley, L. C., Kirkpatrick, K. M., \& Burgoon, J. M. (2013). Relation of gender, course enrollment, and grades to distinct forms of academic dishonesty. Teaching in Higher Education, 18(8), 895-907. 
Honig, B., \& Bedi, A. (2012). The fox in the henhouse: A critical examination of plagiarism among members of the Academy of Management. Academy of Management learning \& Education, 11(1), 101-123.

Howard, S., Ehrich, J., \& Walton, R. (2014). Perceptions of plagiarism: Modification and Rasch validation of a plagiarism attitude scale. Journal of Applied Measurement, 14(4), 372-393.

Jensen, L. A, Arnett, J. J., Feldman, S. S., \& Cauffman, E. (2002). It's wrong, but everybody does it: Academic dishonesty among high school and college students. Contemporary Educational Psychology, 27, 209-228.

Jiang, H., Emmerton, L., \& McKauge, L. (2013). Academic Integrity and Plagiarism: A Review of the Influences and Risk Situations for Health Students. Higher Education Research \& Development, 32(3), 369-380.

Jurdi, R., Hage, H. S., \& Chow, H. P. H (2011). Academic dishonesty in the Canadian classroom: Behaviours of a sample of university students. Canadian Journal of Higher Education, 41(3), 1-35.

Jurdi, R., Hage, H. S., \& Chow, H. P. H. (2012). What behaviours do students consider academically dishonest? Findings from a survey of Canadian undergraduate students. Social Psychology of Education, 15, 1-23.

Kloda, L., \& Nicholson, K. (2005). Plagiarism detection software and academic integrity: The Canadian perspective. Paper presented at Librarian's Information Literacy Annual Conference (LILAC), Imperial College, London, April 4-6, 2005.

Koh, H. P., Scully, G., \& Woodliff, D. R. (2011). The impact of cumulative pressure on accounting students' propensity to commit plagiarism: An experimental approach. Accounting \& Finance, 51, 985-1005. 
Krumpal, I. (2011). Determinants of social desirability bias in sensitive surveys:

A literature review. Quality \& Quantity, 47, 2025-2047.

Lines, L. (2016). Ghostwriters guaranteeing grades? The quality of online ghostwriting services available to tertiary students in Australia. Teaching in Higher Education, 21(8), 889-914.

Marshall, S., \& Garry, M. (2006). NESB and ESB students' attitudes and perceptions of plagiarism. International Journal of Educational Integrity, 2(1), 26-37.

Martin, D. E., Rao, A., \& Sloan, L. R. (2009). Plagiarism, integrity, and workplace deviance: A criterion study. Ethics \& Behavior, 19(1), 36-50.

McCabe, D., \& Trevino, L. (1997). Individual and contextual influences on academic dishonesty: A multicampus investigation. Research in Higher Education, 38, $379-396$.

Montuno, E., Davidson, A., Iwasaki, K., \& Mori, B. (2012). Academic dishonesty among physical therapy students: A descriptive study. Physiotherapy Canada, 64(3), 245-254.

Mu, C. (2010). "I only cited some of his words": The dilemma of EFL students and their perceptions of plagiarism in academic writing. The Journal of Asia TEFL, 7(4), 103-132.

Murdock, T. B., \& Anderman, E. M. (2006). Motivational perspectives on student cheating: Toward an integrated model of academic dishonesty. Educational Psychologist, 41(3), 129-145.

Newstead, S., A. Franklyn-Stokes, \& Armstead, P. (1996). Individual differences in student teaching. Journal of Educational Psychology 88, (2), 229-41.

Park, C. (2003). In other people's words: Plagiarism by university students-literature and lessons. Assessment and Evaluation in Higher Education, 28(5), 471-488. 
Penketh, C., \& Beaumont, C. (2014). 'Turnitin said it wasn't Happy': Can the regulatory discourse of plagiarism detection operate as a change artefact for writing development? Innovations in Education and Teaching International, 51(1), 95-104.

Pickering, J., \& Hornby, G. (2005). Plagiarism and international students: A matter of values differences? In Proceedings of the 16th ISANA International Conference. Christchurch, New Zealand.

Postle, K. (2009). Detecting and Deterring Plagiarism in Social Work Students: Implications for Learning for Practice. Social Work Education, 28(4), 351-362.

Quah, C. H., Stewart, N., \& Lee, J. W. C. (2012). Attitudes of business students' toward plagiarism. Journal of Academic Ethics, 10(3), 185-199.

Roig, M. (2001). Plagiarism and paraphrasing criteria of college and university professors. Ethics and Behavior, 11, 307-324.

Roig, M., \& Caso, M. (2005). Lying and cheating: Fraudulent excuse making, cheating, and plagiarism. The Journal of Psychology, 139(6), 485494.

Song-Turner, H. (2008). Plagiarism: Academic dishonesty or 'blind spot' of multicultural education? Australian University Review, 50(2), 39-51.

Sowden, C. (2005). Plagiarism and the culture of multilingual students in higher education abroad. ELT Journal, 59(3), 226-233.

Sutherland-Smith, W. (2010). Retribution, deterrence and reform: The dilemmas of plagiarism management in universities. Journal of Higher Education Policy and Management, 32(1), 5-16. 
Tennant, A., \& Conaghan, G. (2007). The Rasch measurement model in rheumatology: What is it and why use it? When should it be applied, and what should one look for in a Rasch paper? Arthritis \& Rheumatism, 57(8), 1358-1362.

Thompsett, A., \& Ahluwalia, J. (2010). Students Turned Off by Turnitin? Perception of Plagiarism and Collusion by Undergraduate Bioscience Students. Bioscience Education, 16(1), 1-15.

Tourangeau, R., \& Yan, T. (2007). Sensitive Questions in Surveys. Psychological Bulletin, 133, 839-883.

Walker, J. (2010). Measuring plagiarism: Researching what students do, not what they say. Studies in Higher Education, 35(1), 41-59.

West, C., \& Zimmerman, D. H. (1987). Doing gender. Gender \& Society, 1(2), 125 151.

West, C., \& Zimmerman, D. H. (2009). Accounting for doing gender. Gender \& Society, 23(1), 112-122.

Whitley, B. E. (1998). Factors associated with cheating among college students: A review. Research in Higher Education, 39, 235-274.

Yardley, J., Rodríguez, M. D., Bates, S. C., \& Nelson, J. (2009). True confessions?: Alumni's retrospective reports on undergraduate cheating behaviors. Ethics \& Behavior, 19(1), 1-14. 